\title{
Derivation of Australian Tropical Marine Water Quality Criteria for the Protection of Aquatic Life from Adverse Effects of Petroleum Hydrocarbons
}

\author{
Yuri Tsvetnenko* \\ Aquatic Science Research Unit, Muresk Institute of Agriculture, Curtin University of Technology, \\ Bentley WA 6102, Australia
}

Received 12 July 1997; revised 18 February 1998; accepted 9 March 1998

\begin{abstract}
The use of data on the water concentration of total petroleum hydrocarbons (TPH) in hazard evaluation for marine biota is hindered by the lack of justified water quality criteria for TPH. Using ecotoxicology data for marine organisms and U.S. EPA guidelines $(1985,1994)$, numerical criteria for $\mathrm{TPH}$ were derived. Acute and chronic toxicity data for marine organisms exposed to water-soluble fractions of oil products were obtained from published materials and the author's investigations. Out of 310 data reviewed and sorted, 82 data for the test temperatures of $20-32^{\circ} \mathrm{C}$ were selected and analyzed. The genus mean acute values (GMAV) were calculated for 15 animal genera belonging to the phyla Chordata, Arthropoda, Mollusca, Annelida. Plant values were obtained for six species of the algae classes Diatom, Chlorophyta and Dinophyta. The GMAVs ranged from 0.2 to $13.1 \mathrm{mg} / \mathrm{L} \mathrm{TPH}$. The considerable variability of data was attributed to differences in toxicity test designs. The EC50 values were adjusted by taking into account the fact that average test concentrations drop during courses of static-renewal and static toxicity tests. These adjustments resulted in a GMAV range of $0.2-5.2 \mathrm{mg} / \mathrm{L}$ with acceptable intergeneric variability. The final acute value derived as the fifth percentile of the set of 15 GMAVs for animals was in the range of $0.168-0.198 \mathrm{mg} / \mathrm{L}$ for the triangular, logistic, and normal distribution models. The advisory water quality criterion (AWQC) derived from these values was $0.007 \mathrm{mg} / \mathrm{L}$. According to the criterion definition, to protect warm water marine organisms from unacceptable effects, an ambient concentration of TPH must not exceed AWQC of $0.007 \mathrm{mg} / \mathrm{L}$. ( $) 1998$ by John Wiley \& Sons, Inc. Environ Toxicol Water Qual 13: 273-284, 1998
\end{abstract}

Keywords: petroleum hydrocarbons; LC50; IC50; ecotoxicology; marine water quality criteria

\section{INTRODUCTION}

Anthropogenic hydrocarbon contamination of the marine environment is a significant concern throughout many countries. The sources of hydrocarbon pollution in marine waters include accidental oil spills from ships and oil extracting field platforms, discharge of oil-contained formation water during oil and gas exploration and production, industrial nonrefinery and refinery

\footnotetext{
*E-mail: rtsvetne@alpha2.curtin.edu.au.
}

runoff, and urban sewage. In Australia, only a few oil spills from shipping have been recorded, and oil spills from offshore production (3 tonnes of hydrocarbons per annum) are relatively small. The major contributors of petroleum hydrocarbons in the ocean are chronic sources of municipal wastewater and urban runoff, which account for 11,500 tonnes or $72 \%$ of total hydrocarbons annually entering the marine environment in Australia (Volkman et al., 1994).

Hydrocarbon water pollution except oil spillage cannot be visually detected without analytical quantifica- 
tion of hydrocarbons. Various methods for determination of total petroleum hydrocarbons (TPH) in water are available for environmental monitoring. The most often used include gravimetric analysis, infrared spectroscopy, and high performance liquid or gas chromatography. However, the use of data on TPH concentration in hazard evaluation for marine biota is hindered by the lack of justified water quality criteria for TPH.

In many countries environmental jurisdictions provide no criteria for TPH in seawater or they provide them in narrative form, which can be misinterpreted and misleading. In the United States final water quality criteria for oil and grease were established in 1976 and since then have not been revised. According to these criteria for protection of aquatic life, the concentration of hydrocarbons in water should not exceed " 0.01 of the lowest continuous flow 96-hour LC50 to several important freshwater and marine species, each having a demonstrated high susceptibility to oil and petrochemicals" (U.S. EPA, 1986; Train, 1979). Narrative water quality criteria in the European Communities Directive (Flanagan, 1990), in Hawaii (Hawaii Department of Health, 1990), and Thailand (Thailand Office of the National Environment, 1989) do not allow petroleum products to be present in such quantities that they form a visible film on the surface of the water, impart a detectable "hydrocarbon" taste to fish, and produce harmful effects in fish. In the Philippines, the criterion for oil and grease in spawning areas for Chanos chanos or "bangus" and similar fish species is $2.0 \mathrm{mg} / \mathrm{L}$ (Philippines Department of Environment and Natural Resources, 1990). In the last Australian water quality guidelines (Australian and New Zealand Environment and Conservation Council, 1992), TPH concentration was not included as a pollution indicator. In Western Australia, the water quality criterion of $0.01 \mathrm{mg} / \mathrm{L}$ for TPH in marine and estuary waters was suggested by the working group of the Environmental Protection Authority in their 30 September 1979 report and since then was used in further publications as an interim value (Western Australian Environment Protection Authority, 1981, 1993).

The fast growing demand for petroleum products by developing industry increases the risk of hydrocarbon pollution of the marine environment and necessitates the revision of water quality criteria for TPH.

The aim of this work was to review the information available to date on the toxicity of TPH for marine and estuarine organisms and use it to derive numerical criteria. The derivation of such criteria for TPH is a big challenge, as this group of compounds comprises a variety of components with different physicochemical and toxicological properties. When using TPH as a measure of toxicant concentration, it is worth remem- bering the inherent limitations of this bulk parameter, which depends on specificity, sensitivity, and accuracy of the analytical method used for its determination. Taking into account the general aggregate nature of this parameter, the water quality criteria for TPH should be considered as a tentative directive in the risk assessment.

\section{MATERIALS AND METHODS}

\section{Methodology for Derivation of Water Quality Criteria}

A methodology specifically designed for derivation of quality criteria for Australian marine waters is still under development. In the present work, the U.S. EPA methodology was used because it is well described and standardized with regard to statistical procedures.

According to this methodology, a sufficient amount of data for the local species is used to derive a criterion continuous concentration (CCC) and a criterion maximum concentration (CMC). CCC is a concentration not to be exceeded by the 96-h average concentration once every $3 \mathrm{yr}$, and $\mathrm{CMC}$ is a concentration not to be exceeded by 1 -h average concentration once every $3 \mathrm{yr}$ (Stephan et al., 1985). CCC is a minimal value out of the final chronic (FCV), plant (PCV), and residue (FRV) values. CMC is one-half of the final acute value (FAV), which, in turn, is the fifth percentile of the set of the genus mean acute values (GMAV) for species representatives of at least eight animal families: two families in the phylum Chordata, one family in a phylum other than Arthropoda or Chordata, (either the Mysidae or Penaeidae family), and four other families.

If there are insufficient data for the local species, an advisory water quality criterion (AWQC) can be derived from available information for local and foreign species studied (U.S. EPA, 1994). AWQC is derived by dividing FAV by a final acute-chronic ratio (FACR). FACR is determined by the procedure described by the U.S. EPA (1985) from the data for at least three species. If there are not enough data available, FACR is assumed to be 25. If necessary, AWQC can be lowered to FRV or to one-half of the lowest EC50 for an important aquatic plant.

\section{Sources of Data}

The bibliographies of literature reviews (Moore and Dwyer, 1974; Hyland and Schneider, 1976; Miller, 1982; Capuzzo, 1987; Markarian et al., 1995) and the database of Australian environmental research (AgRound, 1995) were screened and publications on toxicity of petroleum products were acquired. 
The data on toxicity of some petroleum products from the Northwest Shelf in Western Australia were obtained by Curtin Ecotoxicology Laboratory in 96-h bioassays conducted at $27^{\circ} \mathrm{C}$ with marine unicellular alga Isochrysis sp. and postlarvae of the tiger prawn Penaeus monodon. A water-soluble fraction of a petroleum product was prepared by low energy mixing of the petroleum product and seawater at a ratio 1:9 for $20 \mathrm{~h}$ at room temperature in the dark. After a 4-h separation step, an aqueous phase was used in the bioassays.

\section{Selection Criteria for Data}

The data were evaluated for quality. Data were assigned to a certain category of quality according to the criteria used by Markarian et al. (1995). Only data with "high" and "medium" quality were used.

Because most of the offshore and nearshore ocean waters in Australia are characterized by subtropical and tropical temperature regimes, only toxicity test results obtained at temperatures above $15^{\circ} \mathrm{C}$ were extracted from the references.

To ensure the comparability of results, only studies utilizing a water-soluble fraction (WSF) or a water accommodated fraction (WAF) of petroleum product without its emulsion were used as data sources.

\section{RESULTS AND DISCUSSION}

\section{Available Toxicity Data}

The majority of the data were published in 1974-1983 (Fig. 1). Most of these studies were performed on WSFs prepared by gentle stirring of the water and oil mixture for $20 \mathrm{~h}$ followed by some standing period for phase separation.

A substantial amount of information was obtained at cold temperatures of $0-12^{\circ} \mathrm{C}$ on Alaskan marine organisms. Those data were not taken into consideration.

\section{Petroleum Products Tested}

Some species of crude oils and such refinery products as a diesel fuel and bunker fuels were tested for toxicity in the selected studies (Fig. 2). Most of the tests were performed on crude oils and diesel fuels. Crude oils included South Louisiana crude (C1), Kuwait crude (C2), and four crude oil species from the Northwest Shelf of Western Australia (C3-C6). Two specimens of gas condensate $(\mathrm{G} 1, \mathrm{G} 2)$ from the same region were tested. The diesel fuel was represented by fuel oil No. 2 (D1). Bunker fuels were represented by bunker "C" (B1) and Venezuelan bunker "C" (B2).

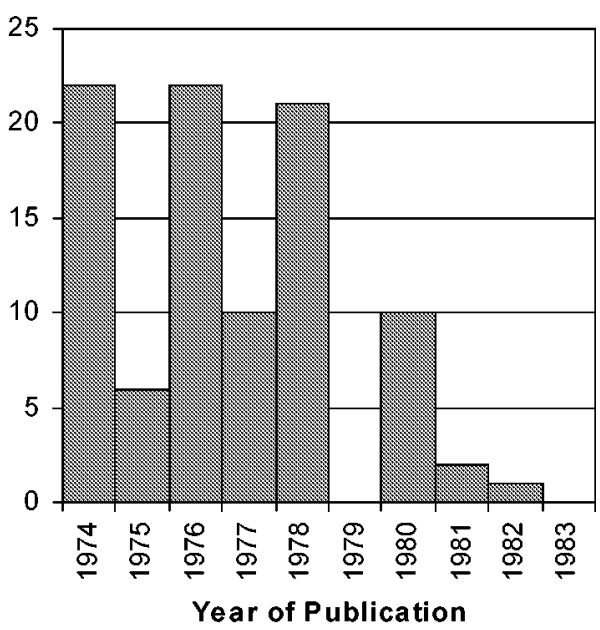

Fig. 1. Number of published acute toxicity data for marine organisms exposed to water-soluble components of petroleum products at warm temperatures.

\section{Conditions of Toxicity Tests}

The toxicity studies varied considerably in terms of test design, lifestage of test organism, temperature, and methodology for measurement and estimation of TPH concentration. These variations are shown in Table I.

A significant amount of information was obtained for solutions with free petroleum product in the form of an emulsion or a slick layer on the water surface. These data deliberately were not used since it was known that water-oil emulsions were always less toxic than petroleum hydrocarbons dissolved in water. Only data obtained in the tests with a water-soluble fraction without free petroleum product were used.

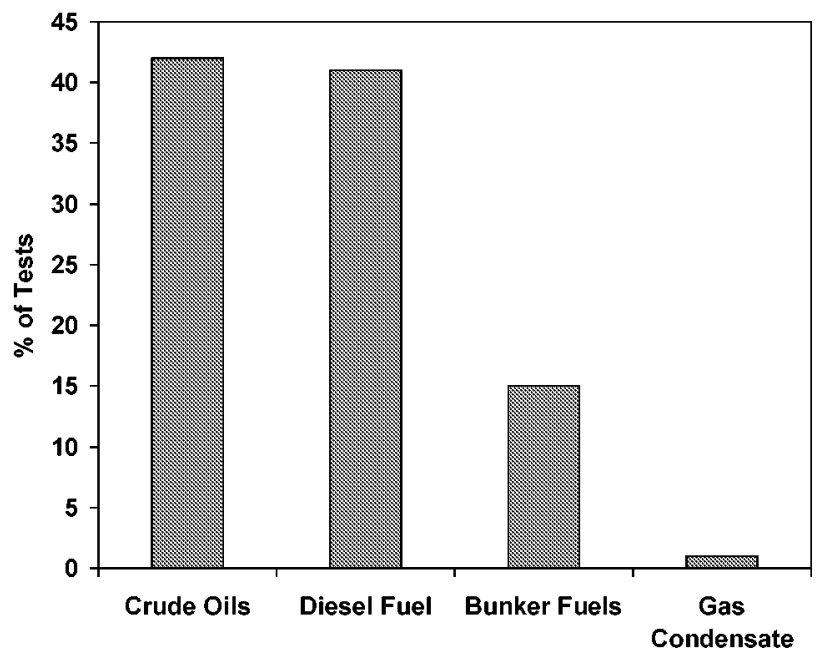

Fig. 2. Petroleum products tested on acute toxicity for marine organisms at warm temperatures. 
TABLE I. Conditions of acute toxicity testing of TPH on marine organisms

\begin{tabular}{|c|c|}
\hline Condition & $\begin{array}{l}\% \text { of } \\
\text { Tests }\end{array}$ \\
\hline \multicolumn{2}{|l|}{ Test design } \\
\hline Flow-through & 1 \\
\hline Static renewal & 9 \\
\hline Static & 89 \\
\hline \multicolumn{2}{|l|}{ Chemical analysis } \\
\hline Gravimetric analysis & 4 \\
\hline Infrared spectrometry & 88 \\
\hline Fluorometry & 1 \\
\hline Gas chromatography & 6 \\
\hline \multicolumn{2}{|c|}{ Test concentration estimation } \\
\hline Initial & 97 \\
\hline Mean & 1 \\
\hline Geometric mean & 1 \\
\hline \multicolumn{2}{|l|}{ Test organism lifestage } \\
\hline Eggs & 1 \\
\hline Larvae & 1 \\
\hline Juveniles & 45 \\
\hline Adults & 52 \\
\hline \multicolumn{2}{|l|}{ Test temperature $\left({ }^{\circ} \mathrm{C}\right)$} \\
\hline $20-<25$ & 84 \\
\hline $25-32$ & 15 \\
\hline
\end{tabular}

Most of the studies were performed by means of static and static-renewal toxicity tests. Very few chronic toxicity tests for petroleum products were conducted at the warm temperature range. Short-term toxicity values LC50 and EC50 produced only in 96-h tests were used.

In most studies the determination of TPH concentration in test solutions was performed using infrared spectrometry. In some cases gravimetric analysis, fluorometry, and gas chromatography were used. All of these methods differ in accuracy, sensitivity, and specificity.

In the majority of the studies an initial test concentration of TPH was used to derive the median lethal or inhibition concentrations. Juvenile and adult organisms were tested in most studies. Most of the warm water tests $(84 \%)$ were conducted at temperatures in the range of $20-25^{\circ} \mathrm{C}$, with the remainder between 26 and $32^{\circ} \mathrm{C}$.

\section{Test Organisms}

At warm temperatures, 70 and 12 toxicity tests were conducted with animal and algal species, respectively (Table II). For each genus, the GMAV was calculated as the geometric mean of all LC50 values. In total, GMAVs were derived for 15 genera, which belonged to phyla Chordata, Arthropoda, Mollusca, and Annelida.
TABLE II. Characteristics of the database of TPH toxicity values for marine organisms tested at warm temperatures

\begin{tabular}{lcc}
\hline Phylum & $\begin{array}{c}\text { Number of } \\
\text { Tests }\end{array}$ & $\begin{array}{c}\text { Number of } \\
\text { Genera }\end{array}$ \\
\hline Chordata & 11 & 3 \\
Arthropoda & 35 & 6 \\
Mollusca & 1 & 1 \\
Annelida & 22 & $\frac{5}{15}$ \\
$\quad$ Total & $\overline{70}$ & 5 \\
\hline
\end{tabular}

For Alga 12 plant inhibitory values were obtained in 96-h toxicity tests as IC50 values.

Among Australian species studied three belonged to phylum Arthropoda, and one belonged to phylum Annelida. The tested algal species included four Australian species.

\section{Toxicity Data Adjustment}

U.S. EPA guidelines (1986) for highly volatile or degradable materials suggest using "only results of flow-through tests in which the concentration of test material in the test solutions were measured often enough." Most petroleum products dissolved in water are highly volatile and degradable. Comparison of chemical data for fresh and expended WSFs of Australian Northwest Shelf crude oils showed that after 24-h exposure, test solutions lost up to $95 \%$ of TPH. Flow-through toxicity tests on petroleum products were employed very seldom because of their high cost. Most results on petroleum product toxicity were obtained from static and renewal tests and were based on initial concentrations. The use of static tests is justified by the assumption that their results reflect the real situation in the environment where petroleum products discharged into the water and their principal water-soluble components are rapidly lost because of volatilization and degradation. However, results for both static and renewal tests cannot be considered acceptable for deriving WQC because they are not uniform.

True estimations of toxicity can be achieved in tests where toxicant concentration is constant. The toxicity data produced for petroleum products in static toxicity tests with aquatic organisms are biased since TPH concentration drops during the course of the tests because of volatility and degradability of some hydrocarbons. The use of initial concentrations results in underestimation of hydrocarbon toxicity to different extents for different temperatures and test designs. To compensate for these differences and normalize toxic- 
ity data, mean concentrations for the entire period of exposure can be used for the calculation of median acute values. The mean concentration of an unstable toxicant is less than the initial concentration and can be calculated providing the pattern of the concentration change during the test exposure period is known. The toxicity value LC50 generated from the mean concentrations can be considered as an approximate toxicity estimation of a product at its constant concentration.

It was shown that a concentration of hydrocarbons dissolved in water decreases exponentially during the first $12 \mathrm{~h}$ of exposure. This decrease depends on the specific gravity of the petroleum product, exposure temperature, and salinity of the water (Hamoda et al., 1989). During this period, in $t \mathrm{~h}$ of exposure, TPH concentration $C_{t}$ in a test solution with an initial TPH concentration $C_{0}$ will be

$$
C_{t}=C_{0} e^{-b_{1} t}
$$

where $b_{1}=K \times \log _{10} e \times 10^{-1}$ is a modified mass transfer coefficient. The latter is calculated from the specific gravity of the petroleum product $\left(\nu,{ }^{\circ} \mathrm{API}\right)$, test temperature $\left(T,{ }^{\circ} \mathrm{C}\right)$, and ionic strength of water $(I)$ :

$$
K=1.68 \times 10^{-5} \times \nu^{1.253} \times T^{1.80} \times e^{-0.144 I}
$$

The ionic strength of sea water at normal atmospheric pressure is given by the empirical expression (Smith, 1974) using salinity $(S, \% o)$ and temperature $\left(T,{ }^{\circ} \mathrm{C}\right)$ :

$$
\begin{aligned}
I= & 0.0054+0.0184 S+1.78 \times 10^{-5} S^{2} \\
& -3.0 \times 10^{-4}(25-T)
\end{aligned}
$$

From the data presented by Hamoda et al. (1989), a decrease of TPH concentration between 12 and $72 \mathrm{~h}$ of exposure can be approximated by the multiplicative function

$$
C_{t}^{*}=C_{12} t^{b_{2}},
$$

where $C_{\mathrm{t}}^{*}$ is TPH concentration in $t \mathrm{~h}(12<t \leqslant 72)$, $C_{12}$ is TPH concentration after $12 \mathrm{~h}$ of exposure, and $b_{2}$ is a slope coefficient interpolated or extrapolated from the analogous coefficients for petroleum products of 11-28 API dissolved in saline water and exposed to air at temperatures of $25-45^{\circ} \mathrm{C}$. These coefficients were calculated from the data presented by Hamoda et al. (1989).

No significant changes were observed in THP concentrations in test solutions in the period between 72 and $96 \mathrm{~h}$ of exposure (Hamoda et al., 1989).

The mean TPH concentration for the whole period of exposure can be calculated as

$$
\tilde{C}_{24}=\left(\int_{0}^{12} C_{t} d t+\int_{12}^{24} C_{t}^{*} d t\right) / 24
$$

and

$$
\tilde{C}_{96}=\left(\int_{0}^{12} C_{t} d t+\int_{12}^{72} C_{t}^{*} d t+24 C_{72}^{*}\right) / 96
$$

for renewal and static tests, respectively.

Using the above equations, each reported toxicity value treated as the initial TPH concentration was converted into the mean value for the given parameters of the test. These mean values were considered as adjusted toxicity values and used to derive GMAVs and FAV.

\section{Data Compilation}

Test conditions and toxicity data were compiled in an Excel electronic spreadsheet with columns for the following parameters:

- Phylum, class (order), family, and species of the test organism

- Resident status for Australian fauna $(\mathrm{Y} / \mathrm{N})$

- Lifestage (E, eggs; L, larvae; J, juveniles; A, adults)

- Petroleum product (C, crude oil; F, fuel oil; D, diesel; $\mathrm{G}$, gas condensate)

- Specific gravity of petroleum product ( $\left.{ }^{\circ} \mathrm{API}\right)$

- Test design (ST, static; SR, static renewal; FT, flowthrough)

- Water salinity (\%o)

- Test temperature $\left({ }^{\circ} \mathrm{C}\right)$

- Reported toxicity value $(\mathrm{mg} / \mathrm{L})$

- Analytical method (GM, gravimetric; FL, fluorometric; IR, infrared spectrometry; GC, gas chromatography)

- Measured concentration (I, initial; F, final; M, mean; $\mathrm{G}$, geometric mean)

- Reference

- Adjusted toxicity value (mg/L)

The data are given in Tables III and IV. Mean toxicity values adjusted according to the above equations are given in Table $\mathrm{V}$ for 18 species and 15 genera.

\section{Final Acute Value Derivation}

The set of 15 GMAVs had a small positive skewness of 0.864. A logarithmic transformation was applied to each GMAV as was recommended for skewed populations (Erickson and Stephan, 1988). According to U.S. EPA procedure for FAV derivation, GMAVs were ranked in increasing order and plotted against their 


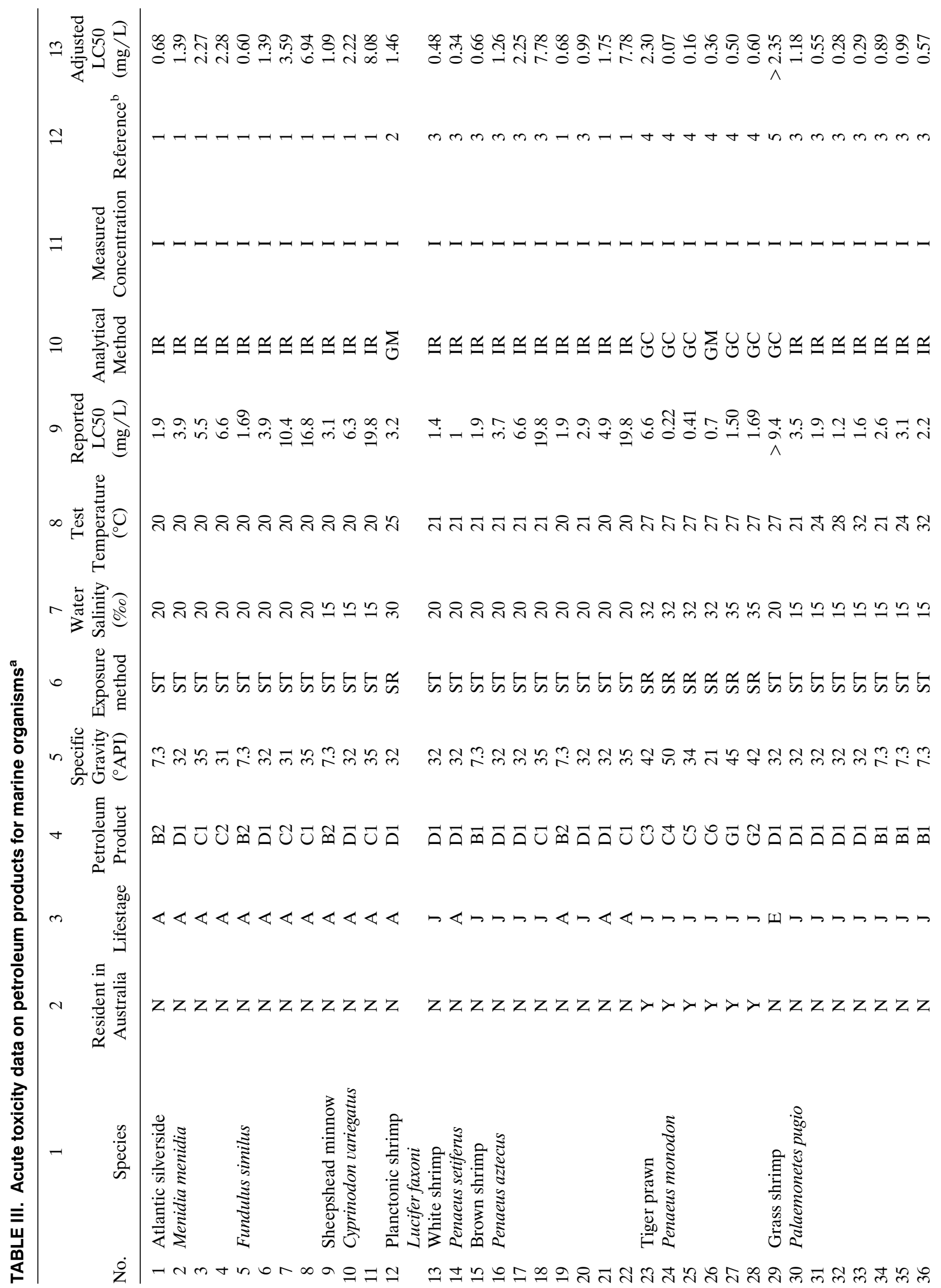




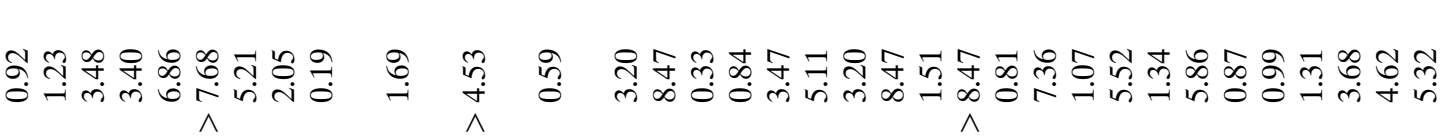

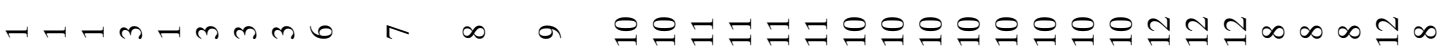

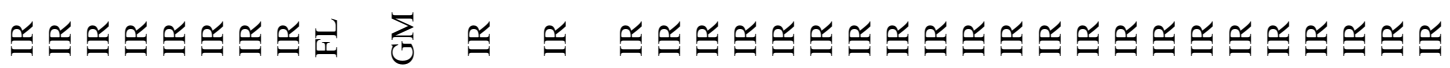

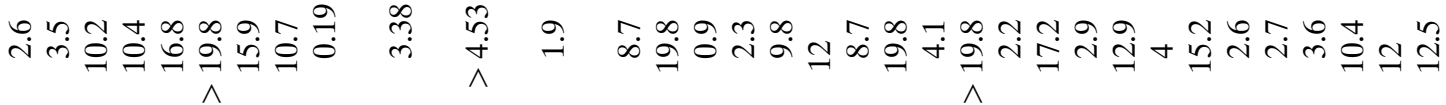

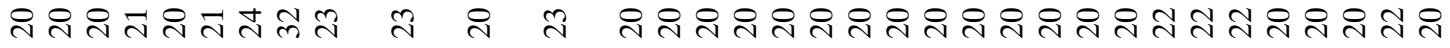

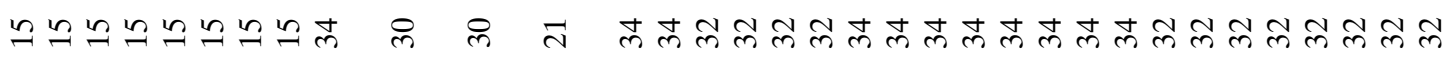

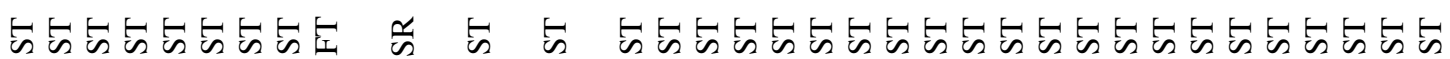

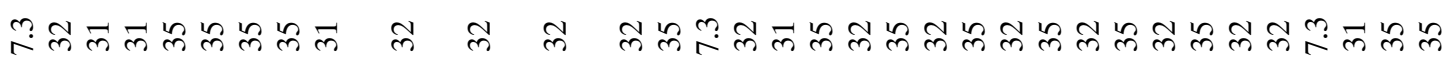

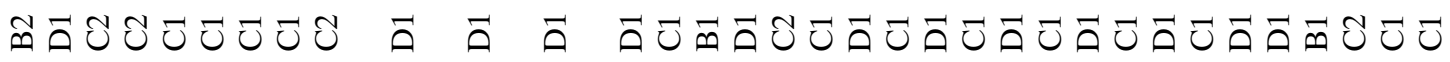

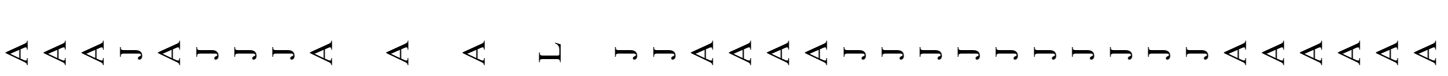

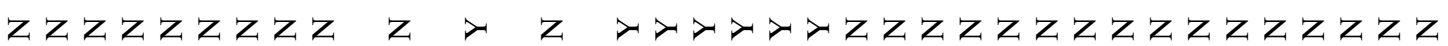
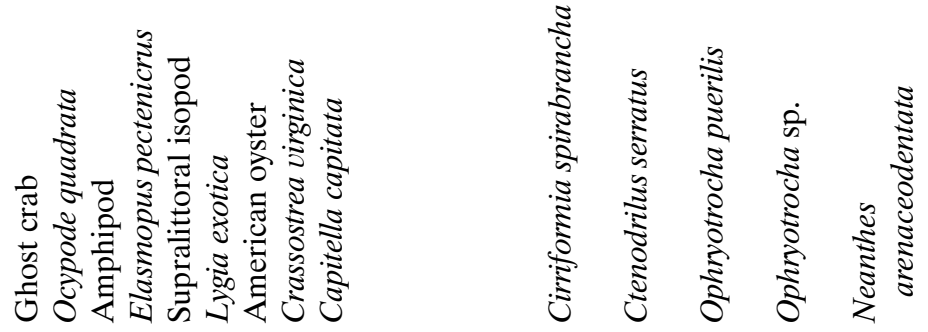

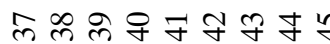




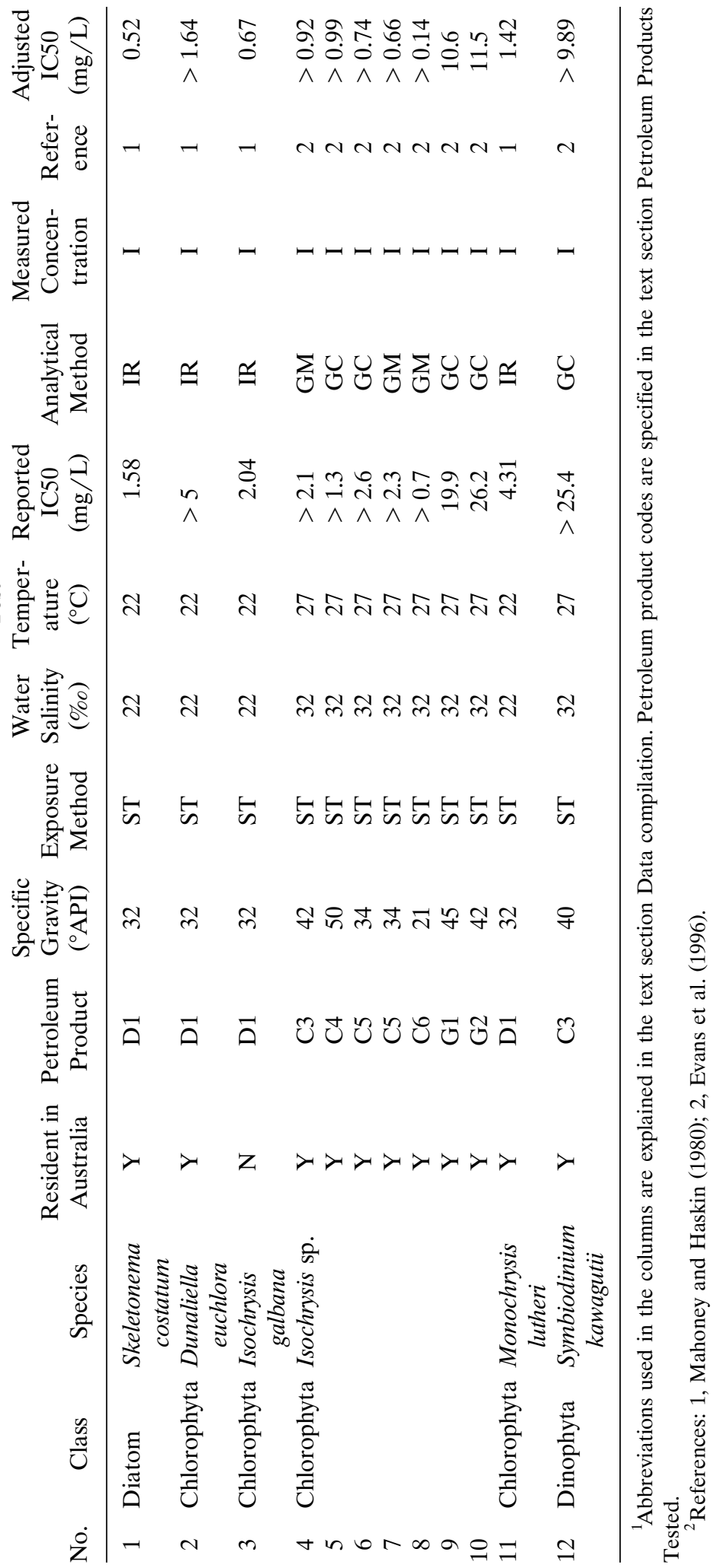


cumulative probabilities (Fig. 3). The cumulative probability was calculated from the rank value $(R)$ and the total number of genera tested $(N=15)$ by Van der Waerden's formula $P_{R}=R /(N+1)$. The square root

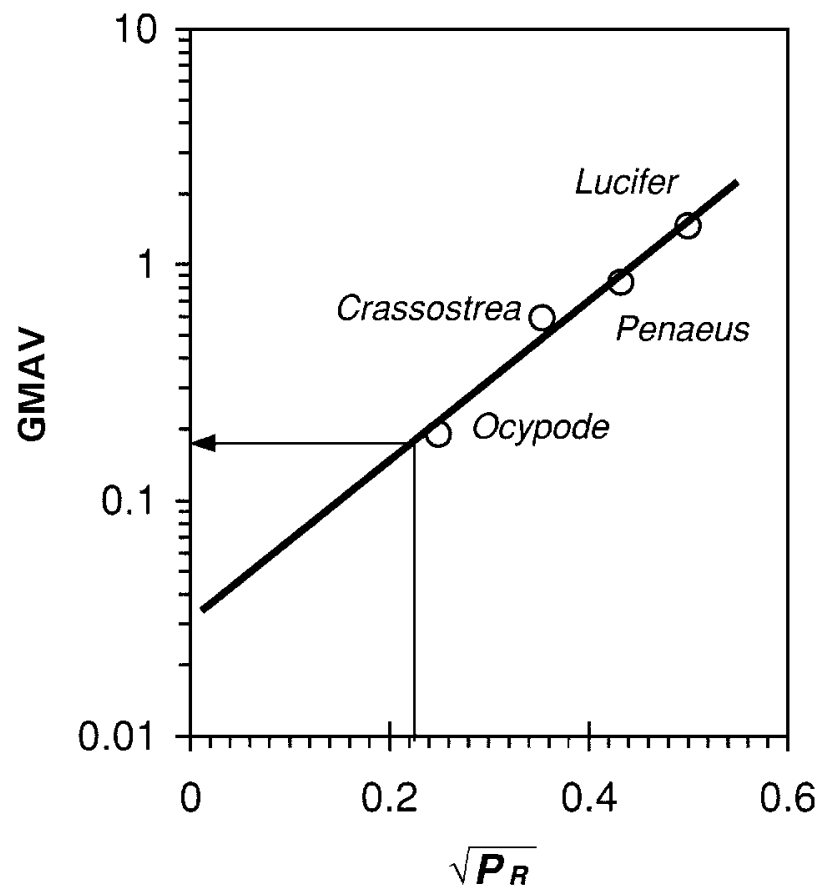

Fig. 3. Plot of four minimal GMAVs against square roots of their cumulative probabilities. The regression line $\operatorname{In}(\mathrm{GMAV})$ $=8.0041\left(P_{R}\right)^{1 / 2}-3.5708$ was used to derive the FAV for $P_{R}=0.05$. scale was used for this variable. Using a special linear regression technique for the four minimal GMAVs and their cumulative probabilities, the FAV was derived as the concentration that corresponds to the cumulative probability of 0.05 . While only the first four GMAV values are used in this procedure to have a range of $P_{R}$ around the point of 0.05 and minimize an error of FAV, the total number of available GMAVs is taken into account in the probability calculation. Out of 15 genera tested (Table V), the following four genera were the most sensitive:

Ocypode, represented by the ghost crab, O. quadrata Crassostrea, represented by the American oyster, $C$. virginica

Penaeus, represented by three species of prawns and shrimps, P. setiferus, P. aztecus, and Western Australian species $P$. monodon

Lucifer, represented by the planctonic shrimp, L. faxoni

The FAV derived from the GMAVs for these genera was $0.168 \mathrm{mg} / \mathrm{L}$.

The FAV derivation procedure used is based on the log-triangular distribution of GMAVs. Log-logistic and log-normal distribution models have been suggested as alternatives for deriving a toxicant concentration value below which $95 \%$ of the taxonomic genera are protected from the harmful effects of the toxicant (Kooijman, 1987; Wagner and Løkke, 1991). The

TABLE V. Adjusted species (SMAV) and genus mean acute values (GMAV) for marine animals exposed to petroleum products

\begin{tabular}{|c|c|c|c|c|c|c|c|}
\hline Phylum & Class & Family & Genus & Species & $\begin{array}{l}\text { Number of } \\
\text { Observations }\end{array}$ & $\begin{array}{l}\text { Adjust. } \\
\text { SMAV } \\
(\mathrm{mg} / \mathrm{L})\end{array}$ & $\begin{array}{l}\text { Adjust. } \\
\text { GMAV } \\
\text { (mg/L) }\end{array}$ \\
\hline \multirow[t]{3}{*}{ Chordata } & \multirow[t]{3}{*}{ Pisces } & Atherinidae & Menidia & menidia & 4 & 1.48 & 1.48 \\
\hline & & \multirow[t]{2}{*}{ Cyprinodontidae } & Fundulus & similus & 4 & 1.77 & 1.77 \\
\hline & & & Cyprinodon & variegatus & 3 & 2.70 & 2.70 \\
\hline \multirow[t]{8}{*}{ Arthropoda } & \multirow[t]{6}{*}{ Decapoda } & \multirow[t]{5}{*}{ Penaeidae } & Lucifer & faxoni & 1 & 1.46 & 1.46 \\
\hline & & & \multirow[t]{3}{*}{ Penaeus } & setiferus & 2 & 0.40 & 0.84 \\
\hline & & & & aztecus & 8 & 1.84 & 0.84 \\
\hline & & & & monodon & 6 & 0.37 & 0.84 \\
\hline & & & Palaemonetes & pugio & 16 & 1.47 & 1.47 \\
\hline & & Ocypodidae & Ocypode & quadrata & 1 & 0.19 & 0.19 \\
\hline & Amphipoda & Melitidae & Elasmopus & pectenicrus & 1 & 1.69 & 1.69 \\
\hline & Isopoda & Lygiidae & Lygia & exotica & 1 & 4.53 & 4.53 \\
\hline Mollusca & Gastropoda & Corambidae & Crassostrea & virginica & 1 & 0.59 & 0.59 \\
\hline \multirow[t]{6}{*}{ Annelida } & \multirow[t]{6}{*}{ Polychaeta } & Capitellidae & Capitella & capitata & 6 & 2.26 & 2.26 \\
\hline & & Cirratulidae & Cirriformia & spirabrancha & 2 & 5.21 & 5.21 \\
\hline & & Ctenodrilidae & Ctenodrilus & serratus & 2 & 3.57 & 3.57 \\
\hline & & \multirow[t]{2}{*}{ Dorvilleidae } & Ophryotrocha & puerilis & 2 & 2.44 & 2.43 \\
\hline & & & & sp. & 2 & 2.43 & 2.43 \\
\hline & & Nereidae & Neanthes & arenaceodentata & 8 & 2.31 & 2.31 \\
\hline
\end{tabular}


Kolmogorov-Smirnov test for goodness of fit (Sokal and Rohlf, 1969) showed that the set of 15 GMAVs had $D$-statistics of $0.182,0.172$, and 0.181 for the triangular, logistic, and normal distributions, respectively. None of these values was greater than the critical value $D_{p<0.05 ; n=15}=0.338$, indicating that any one of the three distributions can be used as the assumed model. The same conclusion was made when the observed data of $\ln$ GMAV $(X)$ with mean value $M$ were compared with expected data $[E(X)]$ for each distribution (Fig. 4). The values of the ratio

$$
\Sigma[X-E(X)]^{2} / \Sigma(X-M)^{2}
$$

used as a measure of goodness of fit are given in Table VI. The lowest ratio value indicating better fit was obtained for the triangular distribution when the number of GMAVs was 4. When the whole set of 15 GMAVs was analyzed, there were no significant differences between the fits to the distributions.

The FAV calculated for 15 GMAVs at the $95 \%$ confidence level was 0.180 and $0.198 \mathrm{mg} / \mathrm{L}$ for logistic (Aldenberg and Slob, 1993) and normal (Wagner and Løkke, 1991) distribution models, respectively. These values are close to the FAV of $0.168 \mathrm{mg} / \mathrm{L}$ derived for the triangular distribution assumption for the subset of four GMAVs.

The similarity between these values generated by the different methods indicates the reliability of FAV for the available data set.

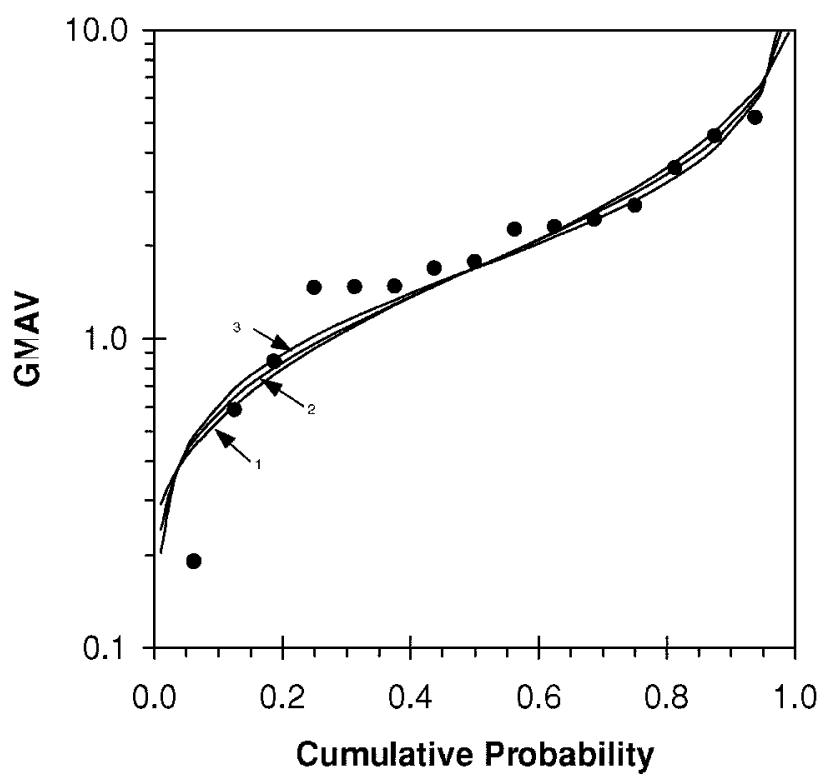

Fig. 4. Distribution of GMAV points and lines of triangle (1), normal (2), and logistic (3) standard cumulative distributions.
TABLE VI. Goodness-of-fit ${ }^{a}$ for $\ln (G M A V)$ data set.

\begin{tabular}{rccc}
\hline \multirow{2}{*}{$\begin{array}{c}\text { Subset } \\
\text { Size }\end{array}$} & \multicolumn{3}{c}{ Distribution Model } \\
\cline { 2 - 4 } & Triangular & Logistic & Normal \\
\hline 15 & 0.120 & 0.121 & 0.120 \\
4 & 0.150 & 0.162 & 0.157 \\
\hline
\end{tabular}

${ }^{\text {a }}$ Goodness-of-fit was calculated as the ratio

$$
\Sigma[X-E(X)]^{2} / \Sigma(X-M)^{2}
$$

where $X$ is the observed $\ln (\mathrm{GMAV}), M$ is the mean of the $\ln (\mathrm{GMAV})$ set with the standard deviation $S$, and $E(X)=M+$ $S \times Z$ is the expected $\ln$ (GMAV) for each distribution. Fractile $Z$ for the cumulative probability $P_{R}$ was calculated for the triangular distribution as

$$
\begin{aligned}
Z & =\left(12 P_{R}\right)^{1 / 2}-(6)^{1 / 2}, & & P_{R} \leqslant 0.5 \\
& =(6)^{1 / 2}-\left(12 P_{R}\right)^{1 / 2}, & & P_{R}>0.5
\end{aligned}
$$

for the logistic distribution as

$$
Z=-(3)^{1 / 2} \ln \left[\left(1-P_{R}\right) / P_{R}\right] / \pi
$$

and for the normal distribution by a built-in function NORM$\operatorname{SINV}\left(P_{R}\right)$ in the Excel computer program.

\section{Final Chronic Value and Advisory Water Quality Criterion Derivation}

The acute-chronic ratios (ACR) of 2.90 and 3.36 could be calculated only for two species of the polychetous annelid, Ctenodrilus serratus and Ophryotrocha sp. (Carr and Reish, 1977), whereas the FACR can be derived from ACRs for at least three species. Because of the lack of data, the FACR was assumed equal to 25 as recommended by the U.S. EPA (1994). This value was a maximum for 93-95\% experimentally determined ACR values (Kenaga, 1982; Slooff et al., 1983; Call et al., 1985). The final chronic values (FCV) for TPH, derived by dividing the FAV by the FACR of 25 , were 7,7 , and $8 \mu \mathrm{g} / \mathrm{L}$ for the triangular, logistic, and normal distributions, respectively. A mean of $7 \mu \mathrm{g} / \mathrm{L}$ can be considered the most appropriate FCV.

The full scheme of the U.S. EPA procedure for deriving WQC requires generating the final residue value (FRV) by dividing a maximum permissible tissue concentration (MPTC) by a bioconcentration factor (BCF). The MPTC is a maximum acceptable dietary intake based on observations of survival, growth, or reproduction in a chronic wildlife feeding study or a long-term wildlife field study. Whereas some data are available for the BCF for petroleum hydrocarbons, there are no data on MPTC. Therefore, the FRV cannot be derived.

The final plant value of $0.14 \mathrm{mg} / \mathrm{L}$ as the lowest IC50 for marine algae (Table IV) was well above the FCV of $0.007 \mathrm{mg} / \mathrm{L}$ and can be excluded from the further consideration. 
The lack of data for local species obviated generating CCC and CMC. The value of $7 \mu \mathrm{g} / \mathrm{L}$ generated as the FCV from the data for the local and overseas species can be considered as the final advisory water quality criterion for TPH.

Australian water quality guidelines are currently being reviewed. These guidelines adopt the Dutch approach for the protection of $95 \%$ of species at $50 \%$ confidence level. By this approach, no observable effect concentration (NOEC) data distributed log-logistically are used for criteria derivation by an extrapolation method (Aldenberg and Slob, 1993). This method was also adopted by OECD (1995) and may be applied if chronic NOEC values are available for at least five different species. As mentioned above, the chronic NOEC data were found only for 2 out of 18 marine animal species tested for tolerance to petroleum products at the temperature range of $20-32^{\circ} \mathrm{C}$. Accordingly, the U.S. EPA approach has been used for AWQC derivation in the present paper.

The background levels for TPH in marine water were reported as the concentrations in the range of 0.3-1.5 $\mu \mathrm{g} / \mathrm{L}$ (Coates et al., 1986; Brown and Searl, 1976). The AWQC calculated in the present study implies that the concentration of TPH in marine water exceeding the background level by more than five times can adversely affect at least $5 \%$ of the species diversity.

In addition, it should be stressed that in this study the petroleum hydrocarbons were considered to be active toxicants only in dissolved form without any free products on the water surface or free product microdroplets in the water column. It was assumed also that the concentration of TPH in water remains constant. Therefore, the concentration of $7 \mu \mathrm{g} / \mathrm{L}$ derived in this exercise is a conservative estimate of WQC for TPH. It can protect aquatic biota in the worst pollution scenarios when dissolved hydrocarbons, for example, are constantly discharged in the environment at a rate that compensates for the loss of volatile and degradable hydrocarbons.

\section{CONCLUSION}

The advisory water quality criterion for TPH in marine and estuarine waters can be formulated as follows: An ambient TPH concentration must not exceed $7 \mu \mathrm{g} / \mathrm{L}$; otherwise, additional data on the concentration of TPH in the effluent or ambient water should be obtained and investigation of site-specific characteristics that could reduce toxicity should be conducted, or acute and/or chronic toxicity tests should be conducted on the whole effluent to demonstrate its low effect on aquatic life, or a new AWQC should be derived after obtaining additional data on the toxicity effects of TPH on marine and estuarine organisms, or concentration should be reduced.

\section{REFERENCES}

AgRound. 1995. Australian Agriculture and Natural Resources CD Database, 5th ed.

Aldenberg, T., and W. Slob. 1993. Confidence limits for hazardous concentrations based on logistically distributed NOEC toxicity data. Ecotoxicol. Environ. Safety 25:48-63.

Anderson, J. W., J. M. Neff, B. A. Cox, H. E. Tatem, and G. M. Hightower. 1974. Characteristics of dispersions and water-soluble extracts of crude and refined oils and their toxicity to estuarine crustaceans and fish. Marine Biol. 27:75-88.

Australian and New Zealand Environment and Conservation Council. 1992. Australian Water Quality Guidelines for Fresh and Marine Waters.

Brown, R. A., and T. D. Searl. 1976. Nonvolatile hydrocarbons in the Pacific Ocean. In Proceedings of the Symposium on Sources, Effects and Sinks of Hydrocarbons in the Aquatic Environment. pp. 240-255. American Institute of Biological Sciences.

Call, D. J., L. T. Brooke, M. L. Knuth, S. H. Poirier, and M. D. Hoglund. 1985. Fish subchronic toxicity prediction model for industrial organic chemicals that produce narcosis Environ. Toxicol. Chem. 4:335-341.

Capuzzo, J. M. 1987. Biological effects of petroleum hydrocarbons: Assessments from experimental results. In D. F. Boesch and N. N. Rabalais (Eds.), Long-Term Environmental Effects of Offshore Oil and Gas Development, pp. 343-410. Elsevier Applied Science Publishers, New York.

Carr, R. S., and D. J. Reish. 1977. The effect of petroleum hydrocarbons on the survival and life history and polychaetous annelids. Fate and Effects of Petroleum Hydrocarbons in Marine Ecosystems and Organisms, pp. 168-173. Pergamon, New York.

Coates, M., D. W. Connell, J. Bordero, G. J. Miller, and R. Back. 1986. Aliphatic hydrocarbons in Great Barrier Reef organisms and environment. Estuarine Coastal Shelf Sci. 23:99-114.

Dillon, T. M., J. M. Neff, and J. S. Warner. 1978. Toxicity and sublethal effects of No. 2 fuel oil on the supralittoral isopod Lygia exotica. Bull. Environ. Contam. Toxicol. 20:320-327.

Erickson, R. J., and C. E. Stephan. 1988. Calculation of the final acute value for water quality criteria for aquatic organisms. National Technical Information Service, Springfield, Virginia.

Evans, L., E. Tsvetnenko, and Y. Tsvetnenko. 1996. Ecotoxicology Studies in North West Australian Marine Organisms. Final Report, Curtin Ecotoxicology Program, Energy Research and Development Corporation. 
Fisher, W. S., and S. S. Foss. 1993. A simple test for toxicity of number 2 fuel oil and oil dispersants to embryos of grass shrimp, Palaemonetes pugio. Marine Pollut. Bull., 26: 385-391.

Flanagan, P. J. 1990. Parameters of water quality. Interpretation and Standards, 2nd ed. Environmental Research Unit, Dublin.

Hamoda, M. F., S. E. Hamam, and H. I. Shaban. 1989. Volatilization of crude oil from saline water. Oil Chem. Pollut. 5:321-331.

Hawaii Department of Health. 1990. Water Quality Standards, Hawaii Administrative Rules. Honolulu, HI.

Hyland, J. L., and E. D. Schneider. 1976. Petroleum hydrocarbons and their effects on marine organisms, populations, communities, and ecosystems. In: Proceedings of the Symposium on Sources, Effects and Sinks of Hydrocarbons in the Aquatic Environment, pp. 464-506. American Institute of Biological Sciences.

Jackson, L. T., W. Bidleman, and W. Vernberg. 1981. Influence of reproductive activity on toxicity of petroleum hydrocarbons to ghost crabs. Marine Pollut. Bull. 12:63-65.

Kenaga, E. E. 1982. Predictability of chronic toxicity from acute toxicity of chemicals in fish and aquatic invertebrates. Environ. Toxicol. Chem. 1:347-358.

Kooijman, S. A. L. M. 1987. A safety factor for LC50 values allowing for differences in sensitivity among species. Water Res. 21:269-276.

Lee, W. Y. and J. A. C. Nicol. 1978. Individual and combined toxicity of some petroleum aromatics to the marine amphipod Elasmopus pectenicrus. Marine Biol. (Berlin) 48: 215-222.

Lee, W. Y., K. Winters, and J. A. C. Nicol. 1978. The biological effects of the water-soluble fractions of a No. 2 fuel oil on the planktonic shrimp, Lucifer faxoni. Environ. Pollut. 15:167-183.

Mahoney, B. M. and H. H. Haskin. 1980. The effects of petroleum hydrocarbons on the growth of phytoplankton recognized as food forms for the eastern oyster, Crassostrea virginica gmelin. Environ. Pollut. 22a:123-132.

Markarian, R. K., J. P. Nicolette, T. R. Barber, and L. H. Giese. 1995. A Critical Review of Toxicity Values and an Evaluation of the Persistence of Petroleum Products for Use in Natural Resource Damage Assessment. Publication 4594, American Petroleum Institute.

Miller, G. J. 1982. Ecotoxicology of petroleum hydrocarbons in the marine environment. J. Appl. Toxicol. 2:88-97.

Moore, S. F., and R. L. Dwyer. 1974. Effects of oil on marine organisms: A critical assessment of published data. Water Res. 8:819-827.

OECD. 1995. Guidance Document for Aquatic Effects assessment. OECD monograph series No. 92, Paris.

Philippines Department of Environment and Natural Resources. 1990. Administrative Order 34. Quezon City, Philippines.

Rossi, S. S., and J. W. Anderson. 1976. Toxicity of water-soluble fractions of No. 2 fuel oil and South Louisiana crude oil to selected stages in the life history of the polychaete, Neanthes arenaceodentata. Bull. Environ. Contam. Toxicol. 16:18-24.

Rossi, S. S., J. W. Anderson, and G. S. Ward. 1976. Toxicity of water-soluble fractions of four test oils for the polychaetous annelids, Neanthes arenaceodentata and Capitella capitata. Environ. Pollut. 10:9-18.

Sigler, M., and L. Lebovitz. 1982. Acute toxicity of oil and bilge cleaners to larval American oysters (Crassostrea virginica). Bull. Environ. Contam. Toxicol. 29:137-145.

Slooff, W., J. H. Canton, and J. L. M. Hermens. 1983. Comparison of the susceptibility of 22 freshwater species to 15 chemical compounds. I. (Sub)acute toxicity tests. Aquatic Toxicol. 4:113-128.

Smith, F. G. W. (Ed.). 1974. Handbook of Marine Science, Vol. I. CRC Press, Cleveland.

Sokal, R. R., and F. J. Rohlf. 1969. Biometry. The Principles and Practice of Statistics in Biological Research. Freeman, San Francisco.

Stephan, C. E., D. I. Mount, D. J. Hansen, J. H. Gentile, G. A. Chapment, and W. A. Brungs. 1985. Guidelines for Deriving Numerical National Water Quality Criteria for the Protection of Aquatic Organisms and Their Uses. U.S. Environmental Protection Agency, Washington, DC.

Tatem, H. E., B. A. Cox, and J. W. Anderson. 1978. The toxicity of oils and petroleum hydrocarbons to estuarine crustaceans. Estuarine Coastal Marine Sci. 6:365-373.

Thailand Office of the National Environment. 1989. Laws and Standards on Pollution Control in Thailand. Bangkok, Thailand.

Train, R. E. 1979. Quality Criteria for Water. Castle House Publications. Billing \& Sons, Guilford, London and Worcester.

U.S. EPA. 1986. Quality Criteria for Water. Publication EPA/440/5-86/001, Office of Water Regulations and Standards. Environmental Protection Agency, Washington, DC.

U.S. EPA. 1994. Guidelines for Deriving Ambient Aquatic Life Advisory Concentrations. Office of Water Regulations and Standards, Washington, DC and Office of Research and Development, Duluth, MN.

Volkman, J. K., G. J. Miller, A. T. Revill, and D. W. Connell, 1994. Oil spills. In: J. M. Swan, J. M. Neff, and P. C. Young, (Eds.), Environmental Implications of Offshore Oil and Gas Development in Australia - The Findings of an Independent Scientific Review, pp. 509-695. Australian Petroleum Exploration Association, Sydney.

Wagner, C., and H. Løkke. 1991. Estimation of ecotoxicological protection levels from NOEC toxicity data. Water Res. 25:1237-1242.

Western Australian Environment Protection Authority. 1981. Water Quality Criteria for Marine and Estuarine Waters of Western Australia. EPA Bulletin 103.

Western Australian Environment Protection Authority. 1993. Western Australian Water Quality Guidelines for Fresh and Marine Waters. EPA Bulletin 711. 